\title{
A Review on Effect of Thermal Factors on Performance of High Power Light Emitting Diode (HPLED)
}

\author{
A. Rammohan ${ }^{1, *}$ and C. Kumar Ramesh ${ }^{2}$

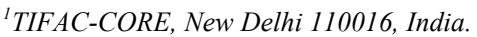 \\ ${ }^{2}$ Department of Automotive Engineering, VIT University, Vellore-632014, India.
}

Received 10 August 2016; Accepted 26 September 2016

\begin{abstract}
The scope of this review paper is to consolidate various thermal factors which affect the performance of high power LEDs and also to summarize various cooling methods which improve both the efficiency and lifetime of LED lamps. Thermal factors such as thermal resistance, thermal spreading resistance, thermal interface material, thermal capacitance, active and passive cooling systems suitable for high power LED packages are discussed. The effect of junction temperature on the colour of emitted light and life of LED is also explored. Junction temperature of the LED depends on the current supplied and type of cooling system used. Higher junction temperature with poor cooling leads to shift in the light colour and drastically reduces the LED life. From the review it was found that heat sink and heat pipes are best solution for heat dissipation and in some applications active cooling systems using electric fan provided best results for LED lamps.
\end{abstract}

Keywords: high power LED; thermal detection; heat sink; active and passive cooling; thermal resistance

\section{Introduction to LED}

From the past decade, high power Light Emitting Diode (LED) plays an important role in the applications like automotive head lights, streetlights, as an indicator for electronic circuits, traffic lights, water disinfection (UVLED), aviation lighting, domestic lighting and in many other applications [2]. Reason for the wide application of these LEDs are low power consumption, long life, compact size and quick response (during ON-OFF switching) compared to conventional lighting systems like incandescent, compact fluorescent lamps (CFL), automotive halogen and xenon lights. LEDs fall under Optoelectronic Devices. Optoelectronics is a technology that combines optics and electronics. This technology includes many devices based on the electron and hole reaction on the $p n$ junction diode. The examples of optoelectronic devices other than LED are photodiodes, optocouplers and laser diodes.

The Figure 1 below shows basic LED circuit which has a voltage source connected to a resistor and LED. The arrows pointing outside in the LED is symbol of emitted light. In the forward bias, the electrons cross over the $p n$ junction and enter into the holes. As electron flow from the higher to lower energy level, they emit light energy as shown in Fig 1 a . In normal pn junction diodes, the energy is radiated as heat. But in the LED, the energy is radiated as light. The wavelength of the light emitted and colour depends on the band gap energy of the materials forming the $p n$ junction. In the same basic LED circuit, resistor $R_{s}$ is current limiting resistor that prevents the supplied (driving) current from exceeding the maximum current rating of the LED. The resistor has node voltage of $\mathrm{V}_{\mathrm{s}}$ and diode has node voltage

*E-mail address: rammohan.a@vit.ac.in

ISSN: 1791-2377 @ 2016 Eastern Macedonia and Thrace Institute of Technology. All rights reserved.
$\mathrm{V}_{\mathrm{d}}$, the voltage across the resistor is the difference between supply voltage $\mathrm{V}_{\mathrm{s}}$ and LED voltage $\mathrm{V}_{\mathrm{d}}$. According to the ohm's law series current is given as is in Equation. 1. LEDs are made of different materials (which are responsible for colour) and are capable to radiate energy on the wide wavelength spectrum available in the chromaticity diagram [49]. The Table.1 clearly shows the wavelength range of light and the colour of the LED with different die material. For example, Gallium Indium Nitride $(\mathrm{GaInN})$ is used as die material for emitting violet colour which has wavelength range of 400 to $500 \mathrm{Nm}$. The forward voltage of LED varies with different types of material and the range lies between 1.6 to $4.4 \mathrm{~V}$ at $20 \mathrm{~mA}$.
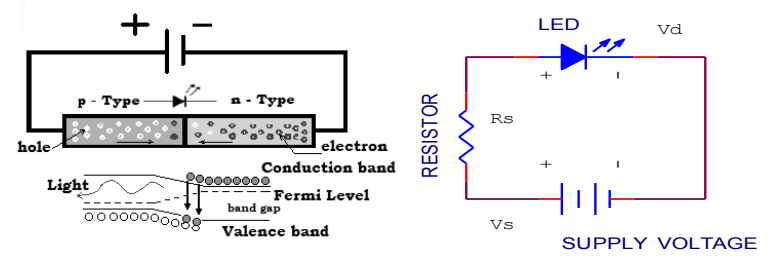

Fig. 1. (a) Electron - hole conduction diagram (b) Basic LED circuit

$\mathrm{I}_{\mathrm{s}}=\frac{V s-V d}{R s}$

The brightness of LED depends on the driving current. The circuit shown in Figure 1 is used to drive SMT type of LEDs which requires maximum power of 40 milli Watts $(\mathrm{mW})$. When $\mathrm{V}_{\mathrm{s}}$ is greater than $\mathrm{V}_{\mathrm{d}}$ as per the Equation. 1, the brightness of LED is almost constant. There are different types current driving sources which are available in the form of monolithic IC's and can be selected based the current capacity of the LED. LEDs work only under forward bias. 
Table 1. Types of LED material, wavelength and colour

\begin{tabular}{|c|c|c|}
\hline Colour & $\begin{array}{l}\text { Wavelengthin } \\
\mathrm{Nm}\end{array}$ & Material \\
\hline $\begin{array}{l}\text { UV - } \\
\text { ultraviolet }\end{array}$ & Less than 400 & $\begin{array}{lr}\text { Aluminium Nitride(AlN), } & \text { Gallium } \\
\text { Aluminium Nitride(AlGaN) and } \\
\text { Aluminium Gallium Indium } \\
\text { Nitride (AlGaInN) }\end{array}$ \\
\hline Violet & $400-500$ & $\begin{array}{l}\text { Gallium Indium Nitride } \\
(\text { GaInN })\end{array}$ \\
\hline Blue & $450-500$ & Silicon carbide $(\mathrm{SiC})$ \\
\hline Green & $500-570$ & $\begin{array}{l}\text { Gallium phosphide (GaP), } \\
\text { Aluminium Gallium Indium } \\
\text { Phosphide (AlGaInP) and } \\
\text { Aluminium Gallium } \\
\text { Phosphide (AlGaP) }\end{array}$ \\
\hline Yellow & $570-590$ & $\begin{array}{l}\text { Gallium Arsenide } \\
\text { Phosphide (GaAsP) }\end{array}$ \\
\hline Orange & $590-610$ & $\begin{array}{l}\text { AluminiumGallium Indium } \\
\text { Phosphide (AlGaInP) }\end{array}$ \\
\hline Red & $610-760$ & $\begin{array}{l}\text { Aluminium } \\
\text { Arsenide } \\
\text { Gallium (AlGaAs), } \\
\text { Phosphide (GaAsP) and } \\
\text { aluminium Gallium Indium } \\
\text { Phosphide(AlGaInP) and } \\
\text { Gallium phosphide }\end{array}$ \\
\hline
\end{tabular}

LEDs are commonly subdivided into Low power LED and High power LED based on power rating [2]. Low power LEDs are operated in milli Wattor micro Watt level. Such kinds of LEDs are used in the electronic appliances to show the operating status of switching in appliances. The high power LEDs those are available in market uses more than $350 \mathrm{~mW}$ of power. Further LEDs are again subdivided into six types based on packaging. They are Surface Mount Through hole (SMT) LED, Surface Mount Devices (SMD) LED, Side LED, TOP LED, High Power LED and Flip Chip LED. The SMT LED is simple to use and cheaper (generally used as indicator lamp in electronic appliances). The SMD LED is also used in the electronic appliances like SMT but it is smaller in size and light weight. The side LED provides light intensity for LCD displays in electronic devices. The TOP LED is similar to SMD LED. It is used as backlight of handsets and Personal Digital Assistant (PDA). A FC LED (Flip-Chip) is manufactured by mounting the LED diode upside down. Flip chip LED uses only gold wire for bonding (for minimising thermal resistance).

High power LEDs produces higher brightness with the help of multichip assembly (array of LEDs) on an aluminium base board. Aluminium base board acts as base as well as a heat sink. The emitting area is located at the centre of LED and each assembly can have up to 40 LEDs on single package. Unlike the SMT based LEDs high power LEDs require separate IC based current drivers for driving the LED under safe region. The challenges in the high power LEDs are high density packaging, luminosity and high thermal conductivity. In addition the thermal factors of the LED directly affect the operating temperature, light energy, total efficiency, wavelength and life. The advantages of high power LED such as good illumination and greater lifetime will decline if the temperature is not properly managed around LED package. Generally the illumination or brightness of LED is measured in Lux or Lumens and life time of LED in hours of operation. A typical bright LED produces light in the range of 30-130 lumen / Watt [1] and life time is about 50000 to 100000 hours.

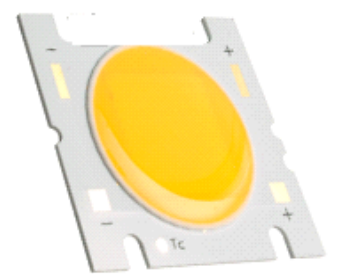

Fig. 2.SMD LED

Life time of LED depends on thermal management, construction or package, operating environment or ambient temperature and driving current from the power source. The efficiency of LED is around 20 to $25 \%$, where only 20 to 25 $\%$ of energy supplied is used for illumination and the rest 75 to $80 \%$ of energy is dissipated as heat. If this heat is not dissipated appropriately, the life time of LED reduces drastically [3].

\section{Construction of High Power LED (HPLED)}

The construction of High Power LED is shown in Figure 3. The top surface of the submount in the LED chip die (also known as $p n$ junction) with the support of die attach is bonded. The die material varies for different illumination colours as given in the Table 2. The sub-mount is bonded to a heat slug with the help of sub-mount adhesive. The die and submount are protected by encapsulation and lens which helps for better refraction. The die and sub-mount along with the encapsulation and lens are attached to the top of ceramic package. The lead frames and heat slug are attached to the MCPCB (Metal core printed circuit board) through thermal slug pad and solder pads respectively. The MCPCB is made up of FR- 4 (Fire retardant) material which acts as an insulator at top and bottom (base) and it is made of aluminium [61]. The insulator on the both sides is used to avoid direct contact between the lead frames and heat slug. The very thin and small size gold conductive wire is used to connect the lead frame and die.

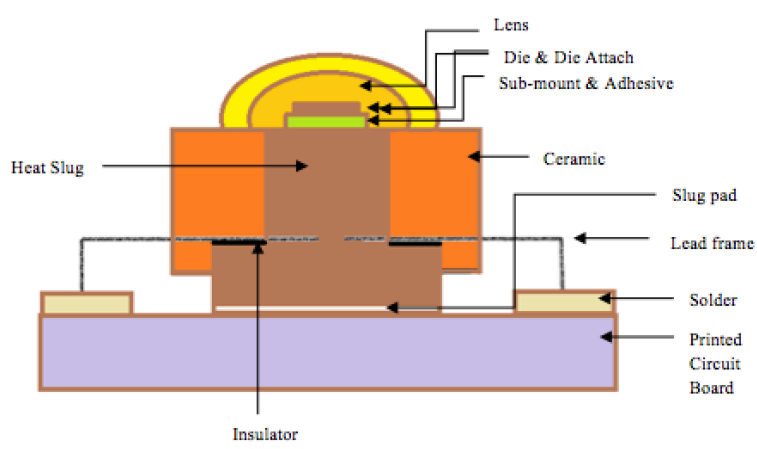

Fig.3.High Power LED construction

In a LED electrical energy is converted into light energy. Approximately 25 to $30 \%$ of total energy supplied is used to illuminate and about 75 to $80 \%$ of energy is dissipated as heat. The die is the major part of LED which is responsible for generating heat due to the supply of the power. 
Dissipation of this heat plays an important role for improving the life and efficiency and the LED. Even though heat slug helps to reduce heat on the package, it may not be sufficient to dissipate the heat generated. The LED may require additional thermal management systems like external forced cooling mechanism to dissipate heat to atmosphere. The dimensions and material properties of typical LED components is shown in Table 2.

\section{Thermal factors of LED}

Inappropriate thermal management is the main reason for reduced life and failure of HPLEDs. To design a proper thermal management heat flow in the LED needs to be familiarised. The heat flow from the die to aluminium base is illustrated with a down arrow [16] in the Figure 4. To attain high luminaire output from LED, high driving current supply is needed and this leads to increase in temperature (due to the conversation of 75 to $80 \%$ electrical supplied electrical energy into heat). If this heat is not dissipated from the junction, the output light or luminous flux will degrade. When the junction temperature is increased, thermal activation of non-radiative electron - hole recombination takes place. This electron hole recombination along with non-radiative recombination causes the degradation of life and luminosity of LED heavily [24].

Table 2. LED material dimension and properties

\begin{tabular}{|c|c|c|}
\hline Part & Material & Dimensions(mm) \\
\hline Encapsulation & Silicone [62] & Diameter: 2 \\
\hline Lens & Polycarbonate[63] & Diameter: 3.5 \\
\hline \multirow[t]{2}{*}{ Insulator } & Thermal Interface & Outer Diameter: 6 \\
\hline & material (TIM) [2] & $\begin{array}{l}\text { Inner Diameter : } 2 \\
\text { Thickness : } 2\end{array}$ \\
\hline MCPCB (top) & FR-4[64] & $40 \times 40 \times 0.2$ \\
\hline Ceramic Package & Ceramic5 [65] & $9 \times 9 \times 3.2$ \\
\hline Thermal slug [70] & $\begin{array}{l}\text { Epoxy thermal } \\
\text { conductive adhesive } \\
{[66]}\end{array}$ & $\begin{array}{l}\text { Diameter : } 6 \\
\text { Thickness : } 0.3\end{array}$ \\
\hline Die attach & Silver Epoxy [67] & $1 \times 1 \times 0.2$ \\
\hline & Gallium Nitride[68] & $1 \times 1 \times 0.2$ \\
\hline Solder & Lead Free $\mathrm{SnAgCu}$ & $1.5 \times 2.13$ \\
\hline Submount Adhesive & Silver Epoxy [67] & $1.5 \times 1.5 \times 0.05$ \\
\hline Lead frames & Steel & $1 \times 0.15$ \\
\hline Submount & Silicon & $1.5 \times 1.5 \times 0.2$ \\
\hline MCPCB (bottom) & Al6061 alloy[69] & $40 \times 40 \times 1.3$ \\
\hline Heat slug & Aluminium & Outer \\
\hline & & Diameter: 6 \\
\hline & & Thickness : 2.1 \\
\hline & & $\begin{array}{l}\text { Inner Diameter: } 3 \\
\text { Thickness: } 1.33\end{array}$ \\
\hline
\end{tabular}

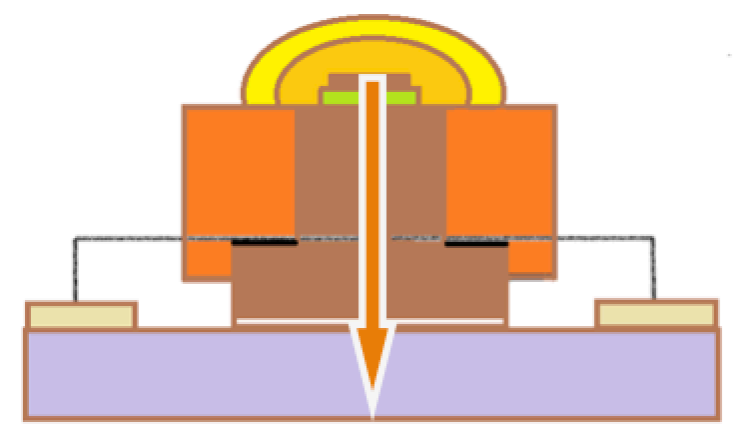

Fig.4.LED - Heat flow path [16]

The change in light output as a function of junction temperature is shown in Figure 5. It is clear that at $85^{\circ} \mathrm{C}$ junction temperature the Luminous flux output is $100 \%$. When the junction temperature rises the luminous flux degrades and any further increase in junction temperature above $150{ }^{\circ} \mathrm{C}$ LED may fail abruptly. In addition, the colour of the LED also changes as the forward voltage decreases due to increase in junction temperature. So for enhanced operation of LED in high temperature environment a better thermal management system is required [31]. The following Figure 5 shows the interaction between temperature, forward voltage, current, dissipated power and light output. For example, the light output or luminosity directly depends on temperature, forward voltage and current. The LED temperature is affected only because of increase in dissipated power.

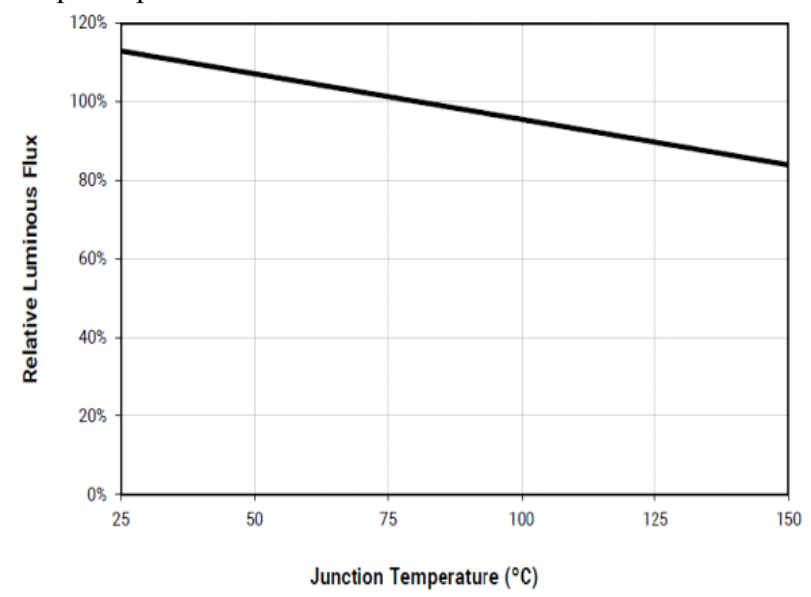

Fig.5.Luminous Flux and junction temperature curve

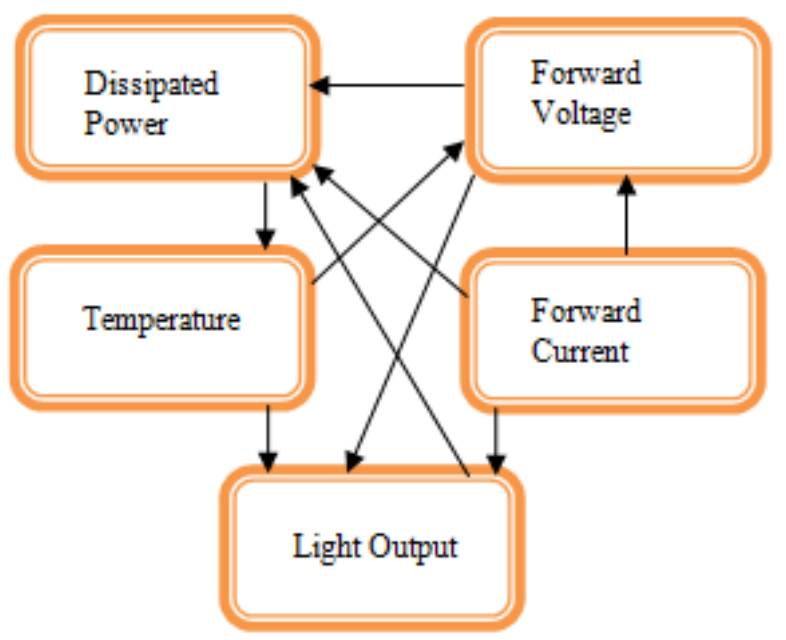

Fig.6.Light output dependency [25][72]

\subsection{Fundamentals of Heat transfer}

It is clear from the previous sections that major part of the supplied energy is converted in to heat and remaining part of supplied input energy is converted to light. The ratio between amount of energy converted to light to supplied energy is called as LED efficiency. The heat liberated from LED (thermal power) is given in Equation. 2. The LED efficiency varies with respect to thermal management.

$\mathrm{P}_{\mathrm{t}}=1-\eta_{L E D} \times \mathrm{V}_{\mathrm{f}} \times \mathrm{I}_{\mathrm{f}}$

where $P_{t}=$ thermal power (heat liberated) in Watts

$\mathrm{V}_{\mathrm{f}}=$ forward voltage in Volts

$\mathrm{I}_{\mathrm{f}}=$ forward current in Ampere 
LED efficiency, $\eta_{L E D}=\frac{\text { optical output equivalent power }}{\text { Electrical Input power }} \times \mathbf{1 0 0}$

Heat sink (thermal management) is employed in a LED to dissipate the heat liberated at the junction to atmosphere through the metal base. Heat transfer occurs in three modes. They are conduction, convection and radiation. The dissipation of heat from the LED depends on these three modes. Conduction is (the dissipation of heat from LED) through direct contact of solid material. This transfer occurs at the molecular level from one body to another when heat energy is absorbed by a surface and causes the molecules of that surface to move more quickly. In the process, they bump into their neighbors and transfer the energy to them; a process which continues as long as heat is added or as long as temperature difference exists. The heat conduction value of a particular material is expressed in the form of thermal conductivity which is abbreviated as $k$. One dimensional heat conduction Equation given in Equation. 3 is used to calculate the heat dissipated through conduction.

$Q_{\text {cond }}=-k A \frac{\mathrm{d} T}{d x}$

where $\mathrm{Q}_{\mathrm{cond}}=$ amount of heat dissipated through conduction in Watts

$\mathrm{k}=$ thermal conductivity of the particular heat sink material in $\mathrm{W} / \mathrm{m} \mathrm{K}$

$\mathrm{A}=$ cross sectional area of the material in $\mathrm{m}^{2}$

$\mathrm{dT}=$ temperature gradient around the material in Centigrade $\mathrm{dx}=$ distance of heat need to travel in meters

Convection is the transfer of heat through the flow of fluids and gases. There are two types of convection natural convection and forced convection. In the natural convection, there is no external sources for the movement of fluids but the forced convection requires external source such like fan, pump for the accelerated movement of the fluids. The quantity of heat transferred through convection is given by the newton's law of cooling.

$\mathrm{Q}_{\text {conv }}=\mathrm{h} \mathrm{A} \Delta \mathrm{T}$

where $_{\text {conv }}=$ amount of heat dissipated through convection in Watts

$\mathrm{h}=$ heat transfer coefficient in $\mathrm{W} / \mathrm{m}^{2} \mathrm{~K}$

$\mathrm{A}=$ surface area of the material in $\mathrm{m}^{2}$.

$\Delta \mathrm{T}=$ temperature gradient around the material in ${ }^{\circ} \mathrm{C}$ is difference between surface temperature and ambient air temperature

Radiation is the heat dissipation through electromagnetic waves and it does not require a medium. The quantity of heat transfer is based on the emissivity of the material used. In a typical LED, this radiation has no effect as the surface area is small and surface temperature is low. Hence it is not considered for the LED system. The heat dissipation by radiation is given by Equation. 5

$\mathrm{Q}_{\mathrm{rad}}=\alpha \varepsilon \mathrm{A}\left(\mathrm{T}_{\mathrm{s}}^{4}-\mathrm{T}_{\mathrm{f}}^{4}\right)$

where $\mathrm{Q}_{\mathrm{rad}}=$ amount of heat dissipated through convection in Watts

$\alpha=$ Boltmann constant $\left(5.67 \times 10-8 \mathrm{~W} / \mathrm{m}^{2} \mathrm{~K}^{4}\right)$

$\varepsilon=$ emissivity of the surface (no dimension)

$\mathrm{A}=$ surface area of the material in $\mathrm{m}^{2}$

$\mathrm{T}_{\mathbf{s}}=$ surface temperature of the material (centigrade)
$\mathrm{T}_{\mathrm{f}}=$ fluid temperature of the medium or ambient air temperature in centigrade

\subsection{LED thermal factors}

Thermal model of LED presented in Figure 7 is in the form of resistor network by considering thermal resistance of involved materials (from LED junction to air). Thermal resistance is the ratio of material length to the product of thermal conductivity of the material and area of the material. Unit of thermal resistance is ${ }^{\circ} \mathrm{C} / \mathrm{W}$. It is also expressed as the ratio between the temperature difference (between material and ambient temperature) and heat loss rate. Thermal resistance directly affects the junction temperature of LED [16]. Higher thermal resistance causes rise in junction temperature and reduce the total illumination and also change the desired colour. The thermal dissipation through any material is directly proportional to the temperature difference between the two ends and inversely proportionally proportional to the thermal resistance. If thermal resistance and heat generated is known temperature of the surface can be calculated by the product of thermal resistance $(\theta)$ and heat generated $\left(\mathrm{Q}_{\mathrm{h}}\right)$. The total thermal resistance is summation of all thermal resistance.

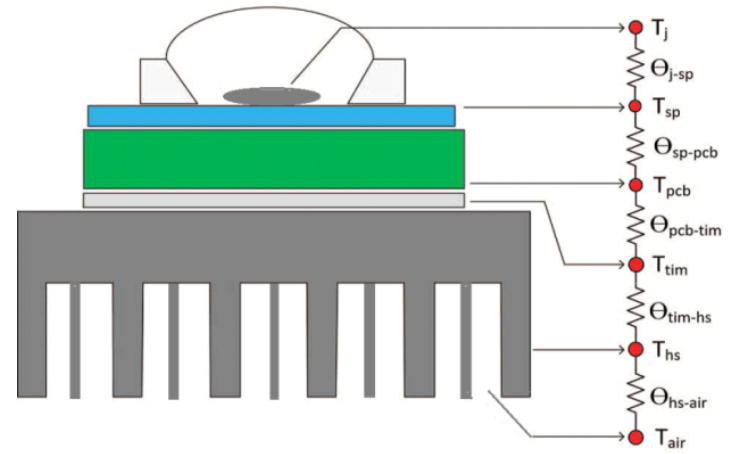

Fig.7.Thermal resistances in LED package

$\mathrm{T}_{\mathrm{j}}=$ Junction temperature

$\theta_{\mathrm{j} \text {-sp }}=$ thermal resistance between junction temperature and solder point

$\mathrm{T}_{\mathrm{sp}}=$ Temperature at solder point

$\theta_{\mathrm{sp}-\mathrm{pcb}}=$ Thermal resistance between solder point and pcb

$\mathrm{T}_{\mathrm{pcb}}=$ Temperature at PCB

$\mathrm{T}_{\text {tim }}=$ Temperature at thermal interface material (TIM)

$\theta_{\text {tim-hs }}=$ Thermal resistance between thermal interface material (TIM) and heat sink

$\mathrm{T}_{\mathrm{hs}}=$ Temperature at heat sink

$\theta_{\text {hs-air }}=$ Thermal resistance between heat sink and air

$\mathrm{T}_{\text {air }}=$ Temperature at air outside the heat sink

$\theta_{\text {pcb-tim }}=$ Thermal resistance between pcb and thermal interface material (TIM)

$\boldsymbol{\theta}_{\text {Total }}=\boldsymbol{\theta}_{\mathrm{j}-\mathrm{sp}}+\boldsymbol{\theta}_{\mathrm{sp}-\mathrm{pcb}}+\boldsymbol{\theta}_{\mathrm{pcb}-\mathrm{tim}}+\boldsymbol{\theta}_{\mathrm{tim}-\mathrm{hs}}+\boldsymbol{\theta}_{\mathrm{hs}-\text { air }}$

All temperatures are measured in ${ }^{\circ} \mathrm{C}$ or $\mathrm{K}$ and all thermal resistances are measured in ${ }^{\circ} \mathrm{C} / \mathrm{W}$ or $\mathrm{K} / \mathrm{W}$. Equation. 6 is used to calculate total thermal resistance for the single chip package. If there is more than one LED in the package the $\theta_{j \text { - }}$ $s p$ and $\theta_{s p-p c b}$ is multiplied with the number of LEDs in the package. The thermal resistance varies with respect to type of die (junction) material, PCB material and type of heat sink used. Junction temperature can be calculated theoretically with this resistance. In a LED package, the LED is soldered to the PCB which is generally a metal core. PCB (MCPCB) or FR4 is attached to the heat sink. In order to maximise the heat dissipation, TIM (thermal interface 
material) is provided in between heat sink and PCB. The best way to maximise the heat dissipation is by reducing number of materials instead using number of thermally conductive materials like TIM in the thermal stack. The total junction temperature is given the following Equation. 7.

$\mathrm{T}_{j}=\mathrm{T}_{s p}+\theta_{t h} \times \mathrm{P}_{t}$

Where

$\mathrm{T}_{j}=$ junction temperature in ${ }^{\circ} \mathrm{C}$

$\mathrm{T}_{s p}=$ measured solder point temperature in ${ }^{\circ} \mathrm{C}$

$\theta_{t h}=$ thermal resistance of the component in ${ }^{\circ} \mathrm{C} / \mathrm{W}$

$\mathrm{P}_{t h}=$ total input power in watts as calculated using Equation.

$(\mathrm{Pt}=0.75 \times$ Vf $x$ If $)$

Yang etal in their investigation concluded that LED thermal resistance varies (due to temperature change) when heat flow path changes [71]. This effect is mainly due to two reasons which are as follows: firstly, change in the thermal conductivity of material with the temperature secondly change in volume due to thermal expansion and contraction of the material. This means, if the LED package with heat sinks is powered up, the LEDs junction temperatures changes along with the LED thermal resistance. Zhi-Yin Lee et al [37] experimented on LED package under constant driving current of $350 \mathrm{~mA}$ and concluded that the as ambient temperature increases, the junction to ambient thermal resistance of an LED package also increase. Hsiang-Chen Hsu et al [27] investigated about face down bonding of LED package which originally originates from the flip-chip packaging design. The necessity to reverse the position of $\mathrm{GaN}$ and sapphire layer is to conduct the heat through bonding layer to dissipative $\mathrm{Si}$ and ceramic substrate instead of sapphire. By this method the more heat can be dissipated.

Qi Lin et al's [34] study concluded that chip substrate material has strong impact on its thermal resistances. Due to high conductivity and thermal expansion of semiconductors, $\mathrm{SiC}$ was found to be best chip substrate than alumina and Copper. Bohan Yan et al [44] demonstrated that in case of white LED, surface temperature measurement can be carried out using an optical method called Phosphor thermometry. This method is used to measure luminescence emitted by phosphor material. Phosphors are a fine white inorganic powder which can be stimulated by emitted light. The phosphor temperature is critical in determining the lumen performance, thermal resistance and life time of white LED emitters. The author finally concluded that Junction temperature alone is not suiTable for concluding the life time of LED. Chien-Ping et al [6] observed the effects of distance, number of chips, and driving current on the thermal resistance of LED module with two-chip and fourchip modules and found phenomenal change in thermal resistance by adjusting distance between the chips and LED driving current. The thermal resistance for calculating the TIM is given in the Equation. 8. The thermal resistance of TIM is directly proportion to the thickness of TIM used. While choosing the TIM, thermal conductivity as well as thermal resistance is needed to be considered for quantifying the total thermal resistance.

\subsection{Thermal spreading resistance}

Thermal spreading resistance incur as the heat flows by conduction from a source to a sink with different crosssectional areas. Spreading resistance increases when a small heat source comes in contact with the base of a large size heat sink. The heat never dissipates uniformly through the heat sink base, and does not transfer efficiently to the fins for convective cooling. The spreading resistance phenomenon is shown by how the heat travels through the exact middle of a heat sink base influencing a large temperature gradient between the center and corners of the heat sink. Jinlong Zhang et al [23] proved that thermal spreading resistance plays a vital role on total thermal resistance of LED devices. The thermal spreading resistance shows a declined and then increased trend based on the following two criteria: the first one is with the increase in substrate thickness and second one is with the increase in contact area of the heat source.

\subsection{Thermal interface material (TIM)}

Thermal interface material is very important layer in a LED package. The significance of TIM is to reduce the air gap (contact resistance) between the PCB and heat sink due to the surface roughness of the contacting surfaces. To fill up these air gaps (voids in the contact area) with a conductive material, thermal interface material is applied as a layer between the contacting surfaces. Also the TIM serves as the electrical insulation between the heat sink material and PCB. The important properties of the TIM and its types are listed in the Table.3.

Table3. TIM types and its properties

\begin{tabular}{l|l|l|l|l|l|l}
\hline $\begin{array}{l}\text { TIM } \\
\text { types }\end{array}$ & $\begin{array}{l}\text { Bulk } \\
\text { conduc } \\
\text { tivity }\end{array}$ & $\begin{array}{l}\text { Ther } \\
\text { mal } \\
\text { resist } \\
\text { ance }\end{array}$ & $\begin{array}{l}\text { Bond } \\
\text { line } \\
\text { thick } \\
\text { ness }\end{array}$ & $\begin{array}{l}\text { Produ } \\
\text { ction } \\
\text { autom } \\
\text { ation }\end{array}$ & $\begin{array}{l}\text { Rew } \\
\text { ork }\end{array}$ & $\begin{array}{l}\text { Stres } \\
\text { s } \\
\text { remo } \\
\text { val }\end{array}$ \\
\hline $\begin{array}{l}\text { Adhes } \\
\text { ive } \\
\text { films }\end{array}$ & Good & Poor & Fair & Fair & Poor & Fair \\
$\begin{array}{l}\text { Adhes } \\
\text { ives }\end{array}$ & Good & Good & $\begin{array}{l}\text { Excel } \\
\text { lent }\end{array}$ & $\begin{array}{l}\text { Excell } \\
\text { ent }\end{array}$ & Poor & Fair \\
$\begin{array}{l}\text { Gap } \\
\text { fill } \\
\text { pads }\end{array}$ & $\begin{array}{l}\text { Excelle } \\
\text { nt }\end{array}$ & Fair & Poor & Fair & $\begin{array}{l}\text { Goo } \\
\mathrm{d}\end{array}$ & $\begin{array}{l}\text { Excel } \\
\text { lent }\end{array}$ \\
$\begin{array}{l}\text { Gels } \\
\begin{array}{l}\text { Ther } \\
\text { mal } \\
\text { grease }\end{array}\end{array}$ & Good & Good & Good & Good & $\begin{array}{l}\text { Goo } \\
\mathrm{d}\end{array}$ & Good \\
\hline
\end{tabular}

$\theta_{\mathrm{TIM}}=\frac{\mathrm{L}}{\mathrm{kA}}$

where

$\theta_{T I M}=$ TIM thermal resistance ${ }^{\circ} \mathrm{C} / \mathrm{W}$

$\mathrm{L}=$ thickness of TIM in meters

$\mathrm{k}=$ thermal conductivity of TIM $(\mathrm{W} / \mathrm{mK})$

$\mathrm{A}=$ contact area in $\mathrm{m}^{2}$

\subsection{Colour temperature}

LEDs emit different colours based on the type junction material used. If these different colours are to be quantified in terms of a numeric value, a term called colour temperature is used. The unit of this measured value is expressed in Kelvin. In another words measuring the hue of white light is called colour temperature. The colour temperature is also known as correlated colour temperature (CCT). The CCT gives the relative colour output of white light, whether the 
output is more yellow or gold (warm white) or more blue (cool white) in range of produced shade of white light.

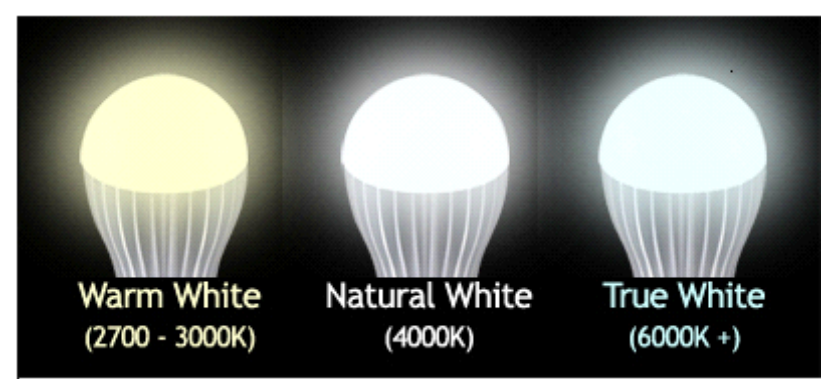

Fig.8.CCT of warm, natural and cool or true white

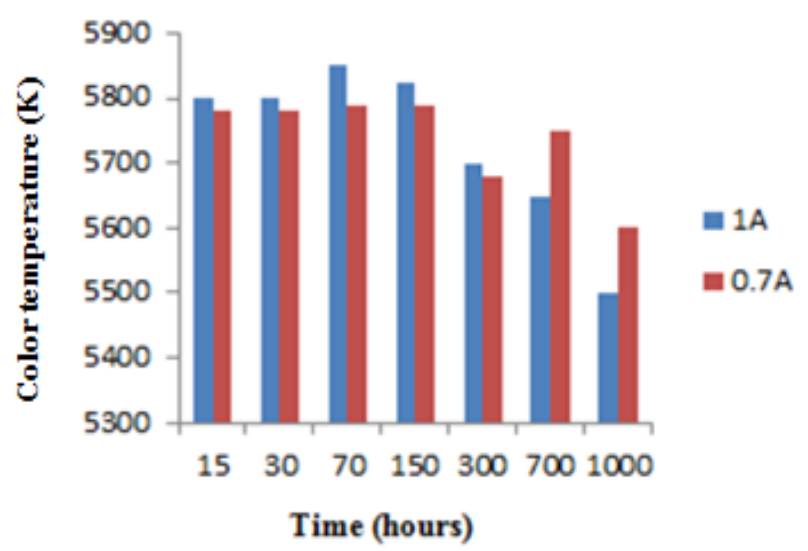

Fig.9.Colour temperature with respect to time in hours at $85^{\circ} \mathrm{C}[15]$

Shih-Chun Yang et al [15] reported in their investigation that the colour temperature drastically reduced from its designed value when it is continuously powered up above 1000 hours. Figure 9 shows the variation of colour temperature with respect to time when junction temperature is maintained at $85{ }^{\circ} \mathrm{C}$. They conducted experiments with different current ratings and at different junction temperature. Under $85{ }^{\circ} \mathrm{C}$, the degradation of colour temperature is fast. Using a three LED packaged module with different colour rendering index (CRI) and correlated colour temperature (CCT) Lei Liu et al [43] demonstrated that the luminous flux, luminous efficacy, colour temperature and forward voltage of a LED get degraded with the rise in junction temperature. In their experiment, the LED junction temperature is maintained at seven levels $25^{\circ} \mathrm{C}, 50^{\circ} \mathrm{C}, 65^{\circ} \mathrm{C}, 75^{\circ} \mathrm{C}, 85^{\circ} \mathrm{C}, 95^{\circ} \mathrm{C}, 100^{\circ} \mathrm{C}$ respectively. Narendran et al [74] conducted experiment to study the colour shift in a commercial high power LED exposed open air, semi ventilated and in enclosure. With increase in junction above $85^{\circ} \mathrm{C}$ and when LED is driven above 1000 hours the authors noted LED colour shift and at certain point abruptly LED fail with poor ventilation (enclosure). The author concluded that LED performance and colour is not guaranteed after 50000 hours for most of the commercial LED's.

The Figure 10 shows the relationship between the junction temperature versus colour temperature and junction temperature versus total radiant flux / W of the LED [76].Using a GaN based LED Weiguo Li et al observed that with the increase in junction temperature LED's total radiant flux reduced and the colour temperature increased [76] as shown in Figure. The radiant flux is energy per unit time radiated from the optical source over optical wavelength.
The optical wavelength is range from $3 \times 10^{11}$ and $3 \times 10^{16}$. The unit of radiant flux is Joules / second or Watts. When the radiant flux is integrated with respect to time, the total energy output $(\mathrm{Q})$ from the source is obtained. The radiant power is more commonly referred to as the "time rate of flow of radiant energy or radiant flux" as given in Equation..9

$\Phi=\frac{d Q}{d t}$

where $\mathrm{Q}$ is radiant energy and $t$ is time. The total amount of current measured over a period of time is directly proportional to the radiant energy absorbed by the light meter (which can measure visible light) during that time. The colour temperature can be measured directly with various portable meters available in the market.

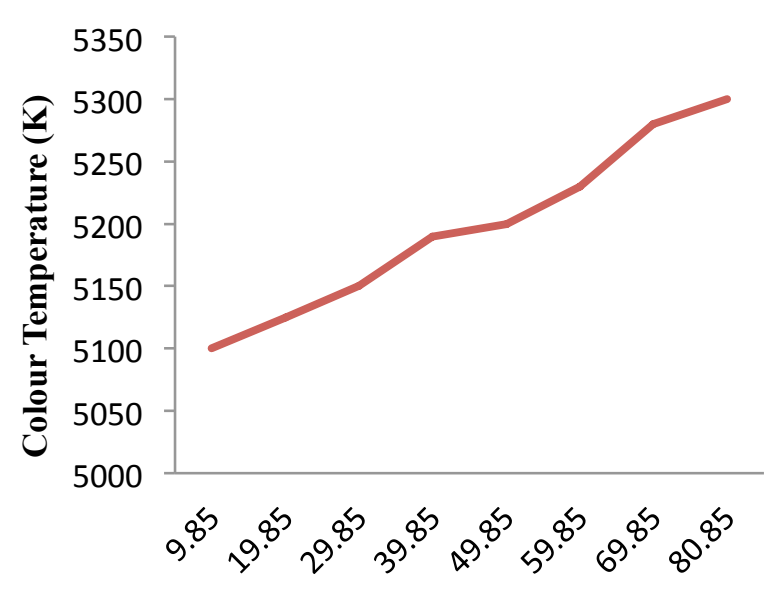

Junction Temperature $\left({ }^{\circ} \mathrm{C}\right)$

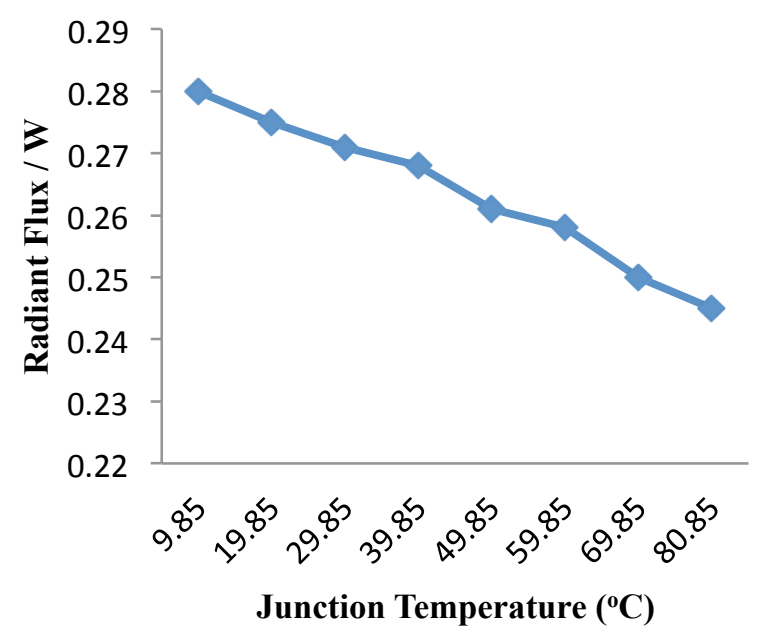

Fig. 10. (a) Colour temperature shift due to junction temperature (b) Radiant flux variation due to junction temperature

\subsection{Thermal Capacitance}

Thermal capacitance is an important thermal factor like thermal resistance which measures the ability of a material to store heat energy. In other words, thermal capacitance is the measure of temperature variation in a material based on its specific heat and mass of the material. Generally it is the quantity of heat energy absorbed or released by a material. Thermal capacitance greatly depends on the specific heat and the density of a material. Thermal resistance is increased with decrease in ambient temperature whereas thermal capacitance decreases with increase in ambient temperature 
[36]. The relation between the thermal capacitance and thermal resistance is given in Equation.10. Generally thermal capacitance is inversely proportional to thermal resistance [73].

Table 4:Specific heat of different materials

\begin{tabular}{c|c}
\hline Material & KiloJ/Kelvingram \\
\hline Water & 4181.3 \\
Steel & 466 \\
Copper & 385 \\
Aluminium & 897 \\
Silver & 233 \\
Concrete & 880 \\
Air & 1012 \\
\hline
\end{tabular}

$\mathrm{C}=\frac{Q t}{\Delta T}$

$$
\text { where } \quad \begin{aligned}
& \mathrm{C}=\text { thermal capacitance of the material } \\
& \mathrm{T}=\text { thermal difference } \\
& \mathrm{Q}=\text { rate of heat flow } \\
& \mathrm{t}=\text { time }
\end{aligned}
$$

\section{LED passive cooling mechanism:}

\subsection{Heat $\sin k$}

The heat sink is the last stack of the LED package. The heat sink that is attached to a LED should have good thermal conductivity and good emissivity as both these properties help to conduct or move heat outside the package. The thermal conductivity and emissivity varies with heat sink material. Table 5 shows the thermal conductivity and emissivity of different materials that are used as heat sink. Choosing the appropriate heat sink material based on conductivity and emissivity is important and at the same time designing the heat sink is complicated due to cost, weight, manufacturability and available space. The maximum temperature mostly occurs in the middle part of the heat sink [19]. The heat sink for LED is subdivided into Radial heat sink and Extruded heat sink. The heat sink should be designed based on the power rating of the LED.

Table 5. Thermal conductivity and emissivity of heat sink materials at $25^{\circ} \mathrm{C}$ [12]

\begin{tabular}{l|l|l}
\hline Material & $\begin{array}{l}\text { Thermal } \\
\text { conductivity } \\
\text { (Watts/metre } \\
\text { Kelvin) }\end{array}$ & $\begin{array}{l}\text { Emissivity } \\
\text { (approximate) }\end{array}$ \\
\hline Acrylic & 0.2 & 0.94 \\
Aluminium & 204.3 & $0.02-0.9$ \\
Low density & 0.04 & Not applicable \\
polymers & 386 & $0.05-0.8$ \\
Copper & 2200 & 1.0 \\
Diamond & 429 & $0.02-0.074=$ \\
Silver & 16.3 & $0.1-1$ \\
Steel & 0.17 & $0.8-0.9$ \\
Wood & \multicolumn{2}{|l}{} \\
\hline
\end{tabular}

In both radial and extruded heat sinks shown in Figure 11 , LED is mounted at middle of the flat portion. The blades like portion around the LED mounting area are called as fins. In most of the LEDs Aluminium is used as heat sink because of its thermal conductivity and emissivity, cost, availability, light weight and manufacturing process is easier compared to other materials. Jung Chang et al [8] used 230W LED illumination lamp which worked with natural convection heat sink and authors modified the heat sink fin parameters such as fin spacing, height, thickness and LED base plate's materials to achieve optimal heat dissipation. They demonstrated best results with $1.1 \mathrm{~mm}$ thick aluminium fin cooling module, $7.5 \mathrm{~mm}$ of pitch and $3.1 \mathrm{~mm}$ of height which maintained the LED junction temperature less than 75 ${ }^{\circ} \mathrm{C}$. A Heat sink with fins is an advisable choice to dissipate heat power below $10 \mathrm{~W}$ from a cost perspective [47].
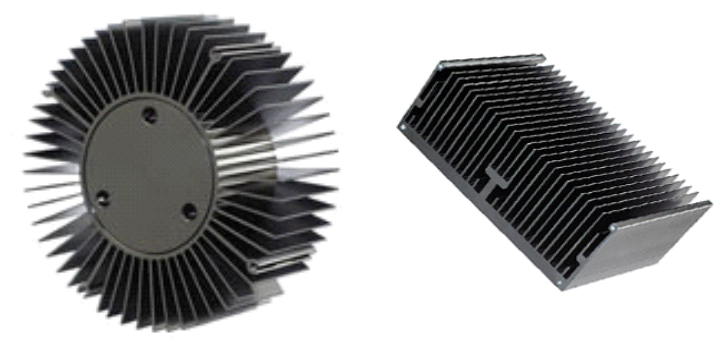

Fig.11.Radial heat sink and Extruded heat sink

M.Y. Tsai et al [10] used an extruded heat sink and analysed the LED Chip On Package (COP) module under natural and forced convection conditions .Their studies concluded that the junction-to-air thermal resistance is sensitive to the air flow conditions, but thermal resistances from the junction to aluminium substrate and to heat sink is not sensitive to air flow conditions. Xin-Jie Zhao et al [9] studied the thermal performance of conventional plate-fin heat sinks and novel cooling device integrated with heat conductive plates (HCPS) for high-power automotive LED headlight. The author considered the thermal resistances of heat conductive plates along with lamp shell used. Dongjing Liu et al [16] investigated that the effect of location and thickness of an aluminium substrate and analysed the thermal resistance and junction temperature of LED. Considering optical power, the total resistance from junction to ambient is found to be 26.19 $\mathrm{K} / \mathrm{W}, 26.45 \mathrm{~K} / \mathrm{W}, 26.84 \mathrm{~K} / \mathrm{W}, 27.06 \mathrm{~K} / \mathrm{W}$ with the aluminium plate positions at middle, top middle, middle left, left and top respectively. The author investigated the thermal resistance based on various orientations. Hao Huang, Miao Caiet al [21] investigated on the thermal resistance of LED module and found that the increased thermal resistance of the solder joint due to poor contact is a key reason that leads to the increasing junction temperature of LED package. Lei Liu et al [47] analysed the variation in characteristics of forward voltage, luminous flux, correlated colour temperatures, luminous efficiency for high-power LED packaging modules under different junction temperatures. They also used the two heat dissipation methods (heat sink with fins and heat pipe with fins) and compared their performance with each other through experimental and numerical simulation. The author found heat pipe with fins are best suitable for very high LED junction temperatures

\subsection{Impact on Heat sink fin orientation}

By changing the orientation of fins, cool air is allowed to flow through the fins. Different orientations may give different results. The effect of changing the orientation angle is shown in Table 6. But the actual performance of a heat sink depends on variables like heat sink location within the assembly, the location of other heat generating elements like power supply, effective airflow, fin spacing, fin height, fin 
thickness, base thickness, base surface area, shape, fin geometry, and overall length.

\subsection{LED Active Cooling mechanisms}

When the quantity of heat is too high, where the passive or heat sink could not dissipate completely, active LED cooling mechanisms are employed to dissipate heat effectively. The active cooling systems includes electric fan, liquid cooling, heat pipes [47] and other methods. While implementing such mechanisms the reliability, cost, noise, external power requirement are to be considered. These cooling systems will further improve the life time of LED with increased cost. With forced air flow using an electric fan Xin-Jie Zhao et al [9] found that the junction temperature decreased gradually from $116.61{ }^{\circ} \mathrm{C}$ to $78.05{ }^{\circ} \mathrm{C}$ as given in Figure 12 . The author also concluded that heat transfer performance of the heat sink has a close correlation with its tilt angles.

Using thermal grease along with heat sink surface of an aluminium case Jong Hwa Choi et al [11] significantly improved the thermal and optical performance of the LED lighting system. The author demonstrated $20 \%$ decrease in junction temperature compared with a basic package without any type of thermal grease as shown in Figure 13. Adam Christensen et al [12] experimented with forced convection cooling system (liquid cooling) and found that the resistances of the package, thermal interface materials and the electrical trace layer (constructed with epoxy dielectric) contributes strongly to the overall thermal resistance. If there is a need to increase the luminous flux for high power LED arrays, the attention should be paid on the highest convective heat transfer coefficients possible while improving the packaging design.

Table 6. Fin orientation and effectiveness

\begin{tabular}{l|l|l|l}
\hline $\begin{array}{l}\text { Fin } \\
\text { Orientation }\end{array}$ & Model & $\begin{array}{l}\text { Effective- } \\
\text { ness }\end{array}$ & $\begin{array}{l}\text { Thermal } \\
\text { Resistance }\end{array}$ \\
\hline Vertical & $99 \%$ & 1.00 \\
Horizontal & $80 \%$ & 2.15 \\
\hline Horizontal & & & \\
\hline
\end{tabular}

Yue Lin et al [14] analysed the change in thermal resistance by using three different LEDs and used a thin and thick copper discs, small polygon shaped and large rectangular aluminium piece. The author found that the thermal resistance is high on the thick copper disc.
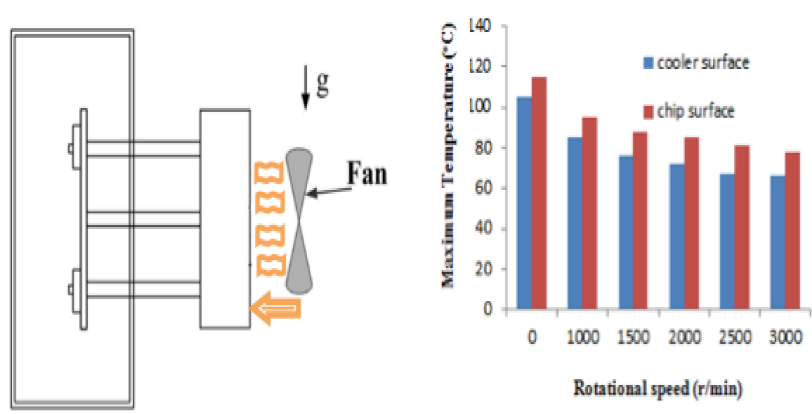

Fig 12.(a) Fan blow direction diagram(b)the effect of the fan rotational speed.

Kazushige Kikuchi et al [58] used pin type and flat fin type heat sink as shown below in Figure 14 and found that straight type heat sink has low junction temperature compared to pin and axial type heat sink. Vitor C. Bender et al [28] used a Closed Cooling System (CCS) using five fans under the heat sink and reported improved thermal dissipation with the increment of the velocity of air. They also analysed the impact on LED driver temperature with and without heat sink. The author found that led driver temperature is less while using heat sink. Sunho Jang et al [52] experimented on a novel cooling system for automotive LED head lamps. The author found that the difference in junction temperature by using the cooling system with fins and without fins was about $4{ }^{\circ} \mathrm{C}$, only marginal difference in temperature was observed by the author with and without fins. They also found that with the increment in air velocity, the maximum temperature decreased about $40{ }^{\circ} \mathrm{C}$. From their data, it was clear that forced air-cooling is the best system which can be used for LED headlamp

Table 7.Types of cooling systems

\begin{tabular}{|c|c|c|c|c|}
\hline Type & $\begin{array}{l}\text { Thermal } \\
\text { dissipati } \\
\text { on } \\
\text { power in } \\
\text { W }\end{array}$ & Details & $\begin{array}{l}\text { Advantag } \\
\text { es }\end{array}$ & $\begin{array}{l}\text { Disadvanta } \\
\text { ges }\end{array}$ \\
\hline $\begin{array}{l}\text { Fan } \\
\text { sink }\end{array}$ & $\begin{array}{l}\text { Less than } \\
40\end{array}$ & $\begin{array}{l}\text { Fan } \\
\text { mount } \\
\text { ed } \\
\text { directl } \\
y \text { on } \\
\text { heat } \\
\text { sink }\end{array}$ & $\begin{array}{l}\text { Inexpensi } \\
\text { ve } \\
\text { compared } \\
\text { to other } \\
\text { cooling } \\
\text { methods }\end{array}$ & $\begin{array}{l}\text { Requires } \\
\text { external } \\
\text { power and } \\
\text { fan fails } \\
\text { entire LED } \\
\text { system need } \\
\text { to replaced }\end{array}$ \\
\hline $\begin{array}{l}\text { Heat } \\
\text { pipe }\end{array}$ & $\begin{array}{l}\text { Less than } \\
140\end{array}$ & $\begin{array}{l}\text { Heat } \\
\text { pipe } \\
\text { need to } \\
\text { attach } \\
\text { to heat } \\
\text { sink }\end{array}$ & $\begin{array}{l}\text { Good heat } \\
\text { dissipatio } \\
\mathrm{n} \text {. No } \\
\text { power } \\
\text { required }\end{array}$ & $\begin{array}{l}\text { Quality } \\
\text { copper } \\
\text { material is } \\
\text { used which } \\
\text { is costlier }\end{array}$ \\
\hline $\begin{array}{l}\text { Liquid } \\
\text { cooling }\end{array}$ & $\begin{array}{l}\text { Less than } \\
200\end{array}$ & $\begin{array}{l}\text { Liquid } \\
\text { used to } \\
\text { surrou } \\
\text { nd the } \\
\text { body } \\
\text { to } \\
\text { dissipa } \\
\text { te heat }\end{array}$ & $\begin{array}{l}\text { High heat } \\
\text { flux } \\
\text { applicatio } \\
\mathrm{n}\end{array}$ & $\begin{array}{l}\text { More } \\
\text { expensive } \\
\text { than heat } \\
\text { pipe }\end{array}$ \\
\hline $\begin{array}{l}\text { Synthet } \\
\text { ic jet } \\
\text { cooling }\end{array}$ & $\begin{array}{l}\text { Less than } \\
80\end{array}$ & $\begin{array}{l}\text { Similar } \\
\text { to fan }\end{array}$ & $\begin{array}{l}\text { Less noise } \\
\text { and better } \\
\text { reliability }\end{array}$ & $\begin{array}{lr}\text { Special heat } \\
\text { sink } \\
\text { needed }\end{array}$ \\
\hline
\end{tabular}



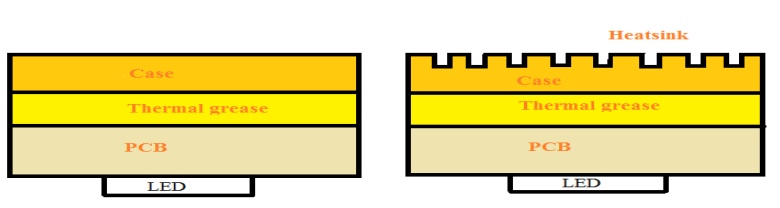

Fig. 13.Cross sectional structures of LED lighting systems with thermal grease between the PCB and the aluminium case (a) and with a heat sink structure (b) in addition to the basic structure [11].
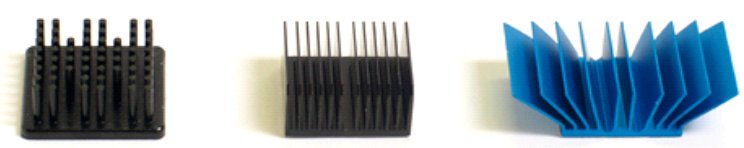

Fig.14. (a) pin heat sink (b) straight heat sink (c) flared fin heat sink

Yan Lai et al [56] in their study reported that for automotive application natural convection was insufficient to maintain junction temperature to required minimum level. Forced convection cooling with air was also not viable due to space and reliability constraints. Authors recommend liquid cooling for automotive applications where the junction temperature is reduced from $200^{\circ} \mathrm{C}$ in natural convection to $110^{\circ} \mathrm{C}$ with liquid cooling. Lan Kim et al [75] observed the junction temperatures of LED array with and without heat pipe. The experiment result shows that with increase in air velocity from $1 \mathrm{~m} / \mathrm{s}$ to $7 \mathrm{~m} / \mathrm{s}$ the junction temperature gradually reduced from $150{ }^{\circ} \mathrm{C}$ to $90{ }^{\circ} \mathrm{C}$ without heat pipe and $95{ }^{\circ} \mathrm{C}$ to $65{ }^{\circ} \mathrm{C}$ for LED array with heat pipe. This clearly shows that heat pipes have good impact in reducing the temperature of LED array.

\section{Thermal detection methods}

It is required to measure the thermal factors to evaluate the LED system before employing it for a particular application. Further measuring such thermal factors in LED accurately is a challenge for the designer. While conducting thermal measurements, LED which is subjected to test need to be considered for worst case scenario. The important factor during testing is time taken for thermal stability. Some LED devices takes even an hour to get stabilise (achieve steady state). Additionally the ambient temperature also needed to be monitored. There are two common methods for monitoring temperature, by using a simple thermocouple and other method is by using an Infrared camera.

\subsection{Thermocouples}

The Figure 15 shows a commercial LED available in market, where the thermocouple is mounted on the solder point when there is no location for mounting a thermocouple coupling. If a separate location is available, thermocouple can be easily mounted on it (in the LED base). Thermally conductive solder is a best way for good heat dissipation from the PCB to thermocouple. Apart from all considerations, the thermocouples need to be error free. In most the thermal measurements an equipment called Thermal Transient Tester (T3ster) [16] [23] [37] [21] [3] [38] is used for testing the thermal resistance at various location of LED package.
Tsp

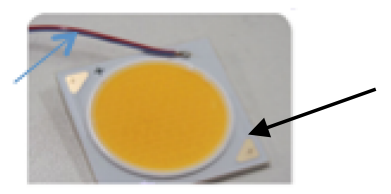

Fig. 15. $T_{s p}$ measurement location

The principle of thermocouple is based Peltier effect. Junction of two dissimilar metals when maintained at a temperature produces emf. This is called as Peltier effect. The junction is connected to a probe tip. The probe tip is contacted to the location where the temperature needs to be measured. When the material composition of the thermocouple changes the thermal detection range also changes as given in the Table 8. Jui-Ching Hsieh et al [13] used $\mathrm{T}$ type thermocouple for thermal measurement (for high accuracy). Jingsong Li et al [4] used thermocouple method along with thermal circuit method and found thermocouple is suitable for measuring thermal resistances. Author verified the thermocouple output along with COMSOL software under simulation and found both the methods are close to each other.

Thomas Poorman et al [60] used thermocouples inside and outside the automotive LED headlamp and concluded the following:

- use small wire thermocouples about 30 gauge

- always route the thermocouple lead along the surface to be measured, minimizing the thermal gradient in the wire and heat flux from the thermocouple junction

- use a thermal interface material (thermal grease) to reduce the thermal resistance between the plastic and the thermocouple junction

\subsection{Infrared Camera method or thermal imaging method}

Every object emits heat energy as a function of their temperature. The heat energy emitted by an object is called as heat signature. Hotter the object more the radiation it emits. A thermal imager or thermal camera is essentially a heat detector that is capable of detecting small difference in temperature. The device collects the infrared radiation from objects spontaneously and creates an image based on information about the change in temperature. This is because systems are rarely in the same temperature with the surrounding objects and the thermal camera can detect them and convert the difference as thermal image. IR camera thermal detection method is best when there is requirement of quick representation of hot spots over the LED package. Infrared imaging temperature measurement has advantages of accurate measurement, non-contact, no damage to LED structure and it is real-time [41]. Basically thermal images are grayscale in nature and latest systems produce colour images which can easily analyse the hot spots in the obtained image. FeiYuan et al [3] proposed accelerated test on high efficiency LEDs with high ambient temperature and high operating current stress. After 800 hours of the accelerated testing, the aging characteristics of thermal resistances were studied. It was found that the die attach quality has strong influence of thermal management of LED packages. It was concluded by the author that the accelerated testing is a very useful method to validate the die attach reliabilities.

PetkoMashkov et al [46] used infrared thermography for investigation of temperature fields on the extruded heat sink and LED. Based on the thermal images captured, their design achieved lower junction temperature which guarantee 
long lifetime (over 50000 hours) during heaviest operating conditions. Jui-Ching Hsieh et al [13] [7] used an IR camera (NEC TH7102MX) to measure the temperature distribution of the holder. Before using thermal infrared camera to measure temperature distribution, the emissivity of holder materials needs to be set. Three thermocouples were pasted on the surface of the holder to measure temperature for verification. The thermal infrared camera also monitored the temperature at the same time. Shih-Chun Yang et al [15] analysed the electrical stress and the thermal stress which has an effect on the LED failure mechanisms. The author used a thermal imager to understand the hot spots which rose due these stress on the LED. They also recorded a phenomenal change in current and light output due to these stresses using IR camera

Table 8. Types of thermocouples

\begin{tabular}{|c|c|c|}
\hline $\begin{array}{l}\text { Thermocouple } \\
\text { Type }\end{array}$ & Composition & $\begin{array}{l}\text { Temperature } \\
\text { Range }\end{array}$ \\
\hline \multirow[t]{2}{*}{ B } & $\begin{array}{l}\text { Platinum 30\% Rhodium } \\
(+)\end{array}$ & $\begin{array}{l}2500-3100^{\circ} \\
\mathrm{F}\end{array}$ \\
\hline & Platinum 6\%Rhodium (-) & $\begin{array}{l}1370-1700^{\circ} \\
\mathrm{C}\end{array}$ \\
\hline \multirow[t]{4}{*}{$\mathrm{C}$} & W5Re Tungsten $5 \%$ & $3000-4200^{\circ}$ \\
\hline & Rhenium (+) & \\
\hline & W26Re Tungsten $26 \%$ & $1650-2315^{\circ}$ \\
\hline & Rhenium (-) & $\mathrm{C}$ \\
\hline \multirow[t]{2}{*}{$\mathrm{E}$} & Chromel $(+)$ & $200-1650{ }^{\circ} \mathrm{F}$ \\
\hline & Constantan (-) & $95-900^{\circ} \mathrm{C}$ \\
\hline \multirow[t]{2}{*}{$\mathrm{J}$} & Iron $(+)$ & $200-1400^{\circ} \mathrm{F}$ \\
\hline & Constantan (-) & $95-760^{\circ} \mathrm{C}$ \\
\hline \multirow[t]{2}{*}{$\mathrm{K}$} & Chromel (+) & $200-2300^{\circ} \mathrm{F}$ \\
\hline & Alumel (-) & $95-1260^{\circ} \mathrm{C}$ \\
\hline \multirow[t]{2}{*}{ M } & Nickel $(+)$ & $32-2250^{\circ} \mathrm{F}$ \\
\hline & Nickel (-) & $0-1287^{\circ} \mathrm{C}$ \\
\hline \multirow[t]{2}{*}{$\mathrm{N}$} & Nicrosil $(+)$ & $1200-2300^{\circ}$ \\
\hline & Nisil (-) & $\begin{array}{l}\mathrm{F} \\
650-1260{ }^{\circ} \mathrm{C}\end{array}$ \\
\hline \multirow[t]{3}{*}{$\mathrm{R}$} & Platinum $13 \%$ & $1600-2640^{\circ}$ \\
\hline & Rhodium (+) & $\mathrm{F}$ \\
\hline & Platinum (-) & $870-1450^{\circ} \mathrm{C}$ \\
\hline \multirow[t]{3}{*}{$\mathrm{S}$} & Platinum $10 \%$ & $1800-2640^{\circ} \mathrm{F}$ \\
\hline & Rhodium (+) & $980-1450^{\circ} \mathrm{C}$ \\
\hline & Platinum (-) & \\
\hline
\end{tabular}

$-330-660^{\circ} \mathrm{F}$ $-200-350^{\circ} \mathrm{C}$

Huan-Ting Chen et al [26] presented a modelling technique for LED systems with LED arrays comprising of non-identical LED devices (all the LED has non-identical optical-thermal-electrical properties). The model provided an accurate prediction of the temperature distribution, luminous flux, and correlated colour temperature of the LED systems. The temperature distribution and light output of the LED systems have been measured using an infrared imaging system and a spectrophoto colorimeter.

Table 9. Thermal nature with greyscale image

Colour in greyscale image Thermal nature

\begin{tabular}{ll} 
Black & Cold \\
White & Hot \\
Grey & Between hot and cold \\
\hline
\end{tabular}

\section{Conclusion}

Thermal factors such as thermal resistance and thermal capacitance at different location of the LED package are the main cause of LED degradation. The temperature change in the LED is mainly due to forward voltage, forward current from the source and ambient temperature. The change in driving parameters and junction temperature directly affects the luminous output and also degrades the life time of LED and shifts the original colour (it is designed for). Various solutions like changing the heat sink size, substrate size and other internal dimensions may improve the heat dissipation. Various active and passive cooling mechanisms which are discussed should be employed not only by considering the LED package, the location where the mechanism is going to operate also needs to be considered. Apart from thermal capacitance and thermal spreading resistance, the colour temperature also needed to be considered on every LED package before using it for particular application.

\section{References}

1. Thermal Simulations of an LED Light Using Comsol Multiphysics - Mika Maaspuro and Aulis Tuominen, University of Turku - 2012 COMSOL Conference in Milan

2. A Parametric Study of a Typical High Power LED Package to Enhance Overall Thermal Performance - Aditya Vipradas, AnandTakawale, Sandeep Tripathi and Vinay Swakul

3. Study on Thermal Degradation of High Power LEDs during High Temperature and Electrical Aging - Fei Yuan, Kailin Pan, Yu Guo, Shujing Chen - 978-1-4799-2250-5/13 - 2013 IEEE

4. Analysis of Thermal Field on Integrated LED Light Source Based on COMSOL Multi-physics Finite Element Simulation Jingsong Li, Qingxin Yang, PingjuanNiu, Liang Jin, Bo Meng, Yang Li, Zhaoxia, Xiao, Xian Zhang- Elsevier Physics Procedia 22 (2011) $150-156$
5. The evaluation for the chromatic characteristics of LED module underelectrical and thermal coupling analysis -Han $\mathrm{Kuei} \mathrm{Fu}, \mathrm{Yi}$ Ping Peng, Shang Pin Ying, TzungTe Chen, Chien Ping Wang, Chiu Ling Chen, Pei Ting Chou -Microelectronics Reliability 53 (2013) 1916-1921-Elsevier

6. Analysis of Thermal Resistance Characteristics of Power LED Module Chien-Ping Wang, Shung-Wen Kang, Kuan-Min Lin, Tzung-Te Chen, Han-Kuei $\mathrm{Fu}$, and Pei-Ting Chou -IEEE TRANSACTIONS ON ELECTRON DEVICES, VOL. 61, NO. 1, JANUARY 2014

7. Evaluation of temperature distribution of LED module -Han-Kuei Fu, Chien-Ping Wang, Hsin-Chien Chiang, Tzung-Te Chen, ChiuLing Chen, Pei-Ting Chou -Microelectronics Reliability 53 (2013) 554-559-Elsevier 
8. Thermal module design and analysis of a $230 \mathrm{~W}$ LED illumination lamp under three incline angles- Jung-ChangWangMicroelectronics Journal (2014) 416-423 - Elsevier

9. Thermal model design and analysis of the high-power LED automotive headlight cooling device Xin-Jie Zhao, Yi-Xi Cai, Jing Wang, Xiao-Hua Li , Chun Zhang - Applied Thermal Engineering xxx (2014) 1-11 -0 - Elsevier

10. Thermal measurements and analyses of low-cost high-power LED packages and their modules -M.Y. Tsai , C.H. Chen, C.S. Kang Microelectronics Reliability 52 (2012) 845-854 - Elsevier

11. Thermal investigation of LED lighting module - Jong Hwa Choi, Moo Whan Shin -Microelectronics Reliability 52 (2012) 830-835Elsevier

12. Thermal effects in packaging high power light emitting diode arrays - Adam Christensen, Samuel Graham - Applied Thermal Engineering 29 (2009) 364-371

13. The optimal design of the thermal spreading on high power LEDs Jui-Ching Hsieh , DavidT.W.Lin , Chin-HsiangCheng , SiwapongKingkaew, Sheng-Chung Chen MicroelectronicsJournal45(2014)904-909

14. Measuring the thermal resistance of LED packages in practical circumstances -Yue Lin, Yijun Lu, Yulin Gao*, Yingliang Chen, Zhong Chen-ThermochimicaActa 520 (2011) 105-109

15. Failure and degradation mechanisms of high-power white light emitting diodes Shih-Chun Yang, Pang Lin , Chien-Ping Wang, Sheng Bang Huang, Chiu-Ling Chen, Pei-Fang Chiang -An-Tse Lee, Mu-Tao Chu -Microelectronics Reliability 50 (2010) 959-964

16. Experimental and numerical approach on junction temperature of high-power LED -Dongjing Liu, Haiying Yang, Ping Yang Microelectronics Reliability 54 (2014) 926-931

17. A Hybrid Prediction Method on Luminous Flux Maintenance of High- Power LED Lamps -Miao Caia, Daoguo Yanga,,Kunmiao Tiana, Xianping Chena, Ping Zhanga, XuejunFanb, Guoqi Zhang Applied Thermal Engineering

18. An LED Driver with Thermal Control Function -ZhenxuZha, Hei Wong -978-1-4799-3282-5 -20 14 IEEE

19. Thermal Management of Power LED System -HakanAkca*, Yusuf Yasa, RamazanAyaz, Ali Durusu, Ali Ajder, Ismail Nakir and MugdesemTanrioven -3rd International Conference on Renewable Energy Research and Applications -IEEE 2014

20. A Comparison Study on Thermal Characterization of High Power LEDs with Different Ceramic Attach Adhesives for Automotive Lighting Applications -P. Anithambigai, D. Mutharasu , T. Zahner, LH. Huong and D. Lacey - IEEE / Therminic 2014

21. Thermal resistance analysis of high power LED module under power cycling test -Hao Huang, Miao Cai, Kunmiao Tian, Yunchao Chen, HongliangJia, Daoguo Yang -2014 15th International Conference on Electronic Packaging Technology -IEEE 2014

22. Is thermal management outside the package enough for higher LED reliability?- Qi Chen, Quan Chen, Run Hu, Xiaobing Luo -IEEE 2014

23. Study on the influencing factors of thermal spreading resistance of HP-LED package -Jinlong Zhang, Luqiao Yin, Peng Song, Yang Bai, Jianhua Zhang -2014 IEEE

24. A review of existing methods for study and analysis of thermal design of LED lighting products -Tanuja S-2013 IEEE

25. Review of methods for reliability assessment of LED luminaires using optical and thermal measurements -Shailesh K R, Ciji Pearl Kurian and Savitha G Kini - 2013 IEEE

26. Chromatic, Photometric and Thermal Modeling of LED Systems WithNonidentical LED Devices -Huan-Ting Chen -2014 IEEE

27. Thermal Design for High Power Arrayed LED Heat-Dissipating System -Hsiang-Chen Hsu1 IEEE Catalog Number: CFP1359BART ISBN: 978-1-4799-0667-3

28. Study on the Thermal Performance of LED Luminaire using Finite Element Method -Vitor C. Bender, OdirlanIaronka and Tiago B. Marchesan -2013 IEEE

29. The Influence of Mutual Thermal Interactions Between Power LEDs on Their Characteristics -IEEE / Therminic 2013

30. Thermal Parameter Extraction Method for Light-Emitting Diode (LED) Systems Xuehui Tao and Dongli Zhang -IEEE 2013

31. LED thermal management of an automotive electronic module with display - S Kesav Kumar -2012 IEEE

32. Transient Analysis of Partial Thermal Characteristics of Multistructure Power LEDs -Chien-Ping Wang, Tzung-Te Chen, Han-Kuei Fu, Tien-Li Chang, and Pei-Ting Chou -IEEE TRANSACTIONS ON ELECTRON DEVICES -MAY 2013
33. Thermal Stability of High-Power LEDs Analyzed With Efficient Nondestructive Methodology -Pei-Hsuan Lee, Jung-Hua Chou, and Hsien-Cheng Tseng -IEEE VOL. 13, NO. 3, SEPTEMBER 2013

34. Thermal Design of a LED Multi-chip Module for Automotive Headlights -Qi Lin, Wang Chunqing, Tian Yanhong- IEEE -2012 International Conference

35. Research on LED Temperature Characteristic and Thermal Analysis at Low Temperatures -Yu Guo, Kai-lin Pan, GuotaoRen,Shu-jingChen,Fei Yuan -IEEE 2012 International Conference

36. Thermal Analysis of Multi-chip LED Package with Different Position and Ambient Temperatures -Sze-Y en Lee, MutharasuDevarajan -2011 IEEE

37. Study on Thermal Behaviour of LED Package at Various Ambient Temperatures -Zhi-Yin Lee, MutharasuDevarajan -2011 IEEE

38. In-situ Analysis of Thermal Properties of Polymer Composites by Embedded LED Temperature Sensor -J. H.Yu, Dmitri Chestakov, Erik Eggink -THERMINIC 2011 - IEEE

39. Experiments and Numerical Simulation on the Performance of LED Subjected to Thermal Shock -XulongGui , and Sheng Liu

40. Thermal Stability Analysis of Power LED During Aging -Anna Andonova, Rumen Yordanov, and Irena Yordanova

41. High power LED thermal performance test analysis and its research methods - Hong min Wang, Haibo Li, Hua Chen and Yu Cao -2011 The 6th International Forum on Strategic Technology

42. Estimation of Optical Power and Heat-Dissipation Coefficient for the Photo-Electro-Thermal Theory for LED Systems -Huanting T. Chen, Xuehui H. Tao, and S. Y. Ron Hui -IEEE -VOL. 27, NO. 4, APRIL 2012

43. Thermal Performance Analysis of photo electric Parameters on High-power LEDs Packaging Modules Dongjing Liu - 2011 12th. into Con! on Thermal. Mechanical and Multiphysics Simulation and Experiments in Microelectronics and Microsystems.EuroSimE 2011

44. Can Junction Temperature Alone Characterize Thermal Performance of White LED Emitters? -Bohan Yan, Nguyen T. Tran, Jiun-Pyng You, and Frank G. Shi, Fellow, IEEE

45. Analysis of Thermal and Luminous Performance of MR-16 LED Lighting Module -Wei-Hao Chi, Tsung-Lin Chou, Cheng-Nan Han, Shin-Yueh Yang, and Kuo-Ning Chiang -IEEE DECEMBER 2010

46. Multifunctional LED Lamp Thermal Management -PetkoMashkov -2010 IEEE

47. Thermal Analysis and Comparison of Heat Dissipation Methods on High-Power LEDs -Lei Liu1, G.Q. Zhang1, Daoguo Yang1, Kailin Pan1, Hong Zhong2, Fengze Hou-2010 IEEE

48. Numerical and experimental study of thermal management on hb led devices - Shao-Shu Chu, Yuen-Ting Wang, Carlos Fernando Moreira Selva -2009 IEEE

49. Thermal Aspects of LED Automotive Headlights-Daniel N. Donahoe, P.E.- 2009 IEEE

50. Design of an LED Thermal System for Automotive Systems -K.F. KWOK B.P. DIVAKAR K.W.E. CHENG -2009 3rd International Conference on Power Electronics Systems and Applications

51. A General Photo-Electro-Thermal Theory for Light Emitting Diode (LED) Systems -S. Y. (Ron) Hui -AUGUST 2009 -IEEEE

52. Thermal Analysis of LED Arrays for Automotive Headlamp With a Novel Cooling System-Sunho Jang and Moo Whan Shin -Thermal Analysis of LED Arrays for Automotive Headlamp With a Novel Cooling SystemSunho Jang and Moo Whan Shin- IEEE 2008

53. Dynamic Thermal Analysis of High-Power LEDs at Pulse Conditions -Lianqiao Yang, Jianzheng Hu, and Moo Whan Shin AUGUST 2008 -IEEE

54. LED Light Emission as a Function of Thermal Conditions -Cathy Biber -2008 IEEE

55. Thermal Management of High-power White LED Package -Qian Cheng -2007 IEEE

56. Thermal Management of Bright LEDs for Automotive Applications-Yan Lai, Nicolás Cordero -2006 IEEE

57. Calculation of Temperature Loads in Headlamps -JuergenWulf 980315- SAE

58. An Approach to Predicting LED Junction Temperatures With Fluid and Thermal Analysis -Kazushige Kikuchi, Yoshihiko Hamashima and Yusuke Kobayashi -2005-01-0864-SAE

59. Thermal Consideration of LED Array for Rear Lamp by Simulation and Measurement -Kazushige Kikuchi and Yuya Iida-2009-010060

60. Evaluating Thermocouple Measurement Techniques for Automotive Lighting -Thomas Poorman, Joseph Bielecki, Mojun Chang and Fadi El Khatib -2004-01-0665 -SAE 
61. Oliver Kückmann, "High power LED arrays Special requirements on packaging technology"

62. B. Han, C. Jang, A. Bar-Cohen, Bongmin Song "Coupled Thermal and Thermo-Mechanical Design Assessment of High Power Light Emitting Diode", IEEE Transactions on Components and Packaging Technologies, vol. 33, issue 4, pp. 688 - 697, 2010.

63. Lexan*9030Sheet Product Datasheet, theplasticshop.co.uk, gilbert curry industrial plastics, http://www.theplasticshop.co.uk/plastic_technical_datasheets/lexan _polycarbonate_9030_technical_properties_data_sheet.pdf

64. Garry Wexler, "Thermal Management Considerations for High Power LED Lighting Applications", Carolina 2011, November 8

65. ANSYS analysis manual (library); ANSYS is a trade mark of ANSYS Inc., Houston, PA, USA

66. KingBright, Part Number: AAD1-9090SY28ZC

67. http://www.kingbrightusa.com/images/catalog/SPEC/AAD1-

9090SY28ZC.PDF, 2012 Feb 15 $5^{\text {th }}$ Technical Bulletin, "40-3900 Silver filled epoxy resin", Epoxies innovative bonding solutions ETC., www.epoxies.com/tech/40-3900R.pdf

68. Huang Jing, Pan Kai-lin, Li Peng, Wang Shuang-ping, "Numerical Analysis of Temperature and Humidity Effects on the Reliability of High Power LightEmittingDiode", Electronic Packaging Technology and High Density Packaging (ICEPT-HDP), 12th International Conference, pp 1-4, 2011

69. www.azom.com/article.aspx?ArticleID=3328, Accessed: 2012 Mar 24 th

70. Application Brief AB10 Assembly InformationLUXEONEMITTER,(Philips Lumileds),www.philipslu LUXEONEMITTER, (PhilipsLumileds), www.philipslumileds.com/uploads/5/AB10-PDF

71. L. Yang, J. Hu, L. Kim, M.W. Shin, Variation of thermal resistance with input power in LEDs, Phys. Stat. Sol. (c) 3 (2006) 2187-2190.

72. AndrasPoppe, "LEDs Standardize - LEDs Do Something Cool", Mentor Graphics, 2012

73. J.C.J. Paasschens, S. Harmsma, R. van der Toorn, "Dependence of thermal resistance on ambient and actual temperature", BipolarlBiCMOS Circuits and Technology, pp. 96-99, Sept 2004.

74. Narendran, N., Deng, L., Pysar, R. M., Gu, Y., Yu, H. (2004): Performance characteristics of high-power light-emitting diodes. Proc. SPIE, 5187, 267-275.

75. Thermal analysis of LED array system with heat pipe - Lan Kim, Jong Hwa Choi, Sun Ho Jang, Moo Whan Shin ThermochimicaActa 455 (2007) 21-25

76. The effect of Temperature on the Color Temperature of GaN-based LED-Weiguo Li, WeilingGuo, Bifeng Cui, Xinwei Xu, Desheng Cui -2011 IEEE 